\title{
Chest helical computed tomography scan shows pulmonary micronodules and condensation in acute schistosomiasis mansoni
}

\author{
Tomografia helicoidal do tórax revela micronódulos e condensação pulmonar na \\ esquistossomose mansônica aguda
}

\author{
Izabela Voieta ${ }^{[1]}$, Luciene Mota Andrade ${ }^{[2]}$ and José Roberto Lambertucci ${ }^{[1]}$
}

[1]. Curso de Pós-Graduacão em Ciências da Saúde: Infectologia e Medicina Tropical, Faculdade de Medicina, Universidade Federal de Minas Gerais, Belo Horizonte, MG. [2]. Serviço de Radiologia, Ecoar Medicina Diagnóstica, Belo Horizonte, MG.

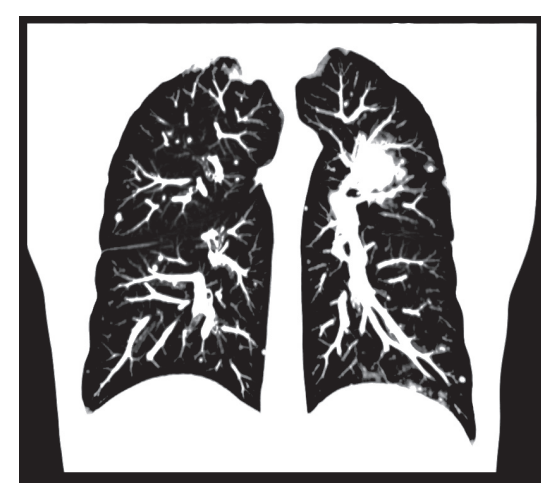

A

A 15-year-old boy developed persistent fever and a diffuse maculopapular rash 21 days before admission to hospital. He was treated with antibiotics and symptomatic drugs without improvement. Clinical examination revealed a well developed underweight teenager, with pale skin. His axillary temperature was $39.3 \circ \mathrm{C}$. There was no history of diarrhea. Abdominal palpation showed painful hepatomegaly and splenomegaly. Leukocytosis $(38,000$ cels $/ \mathrm{mL})$ and eosinophilia $(30,400$ cels $/ \mathrm{mL})$ were found in a routine blood count. Platelet counts and hemoglobin levels were within the normal range and serum alanine aminotransferase was slightly elevated. Abdominal ultrasound showed liver and spleen enlargement and periportal lymph nodes. Schistosoma mansoni eggs were described in the stools. He reported contact with stream water in an endemic area for schistosomiasis 30 days before the start of symptoms. A chest helical computed tomography (CT) scan with multiplanar reconstruction and maximum intension projection (MIP) technique demonstrated bilateral scattered nodules and consolidation in left upper lobe (Figure A). A sagittal reconstruction of left lung showed two consolidations in upper and lower lobes (Figure B; arrows).

Address to: Dr. José Roberto Lambertucci. FM/UFMG. Av. Alfredo Balena 190, 30130-100 Belo Horizonte, MG, Brasil.

Phone: 5531 3337-7781

e-mail: lamber@uai.com.br

Received in 02/08/2012

Accepted in 13/08/2012

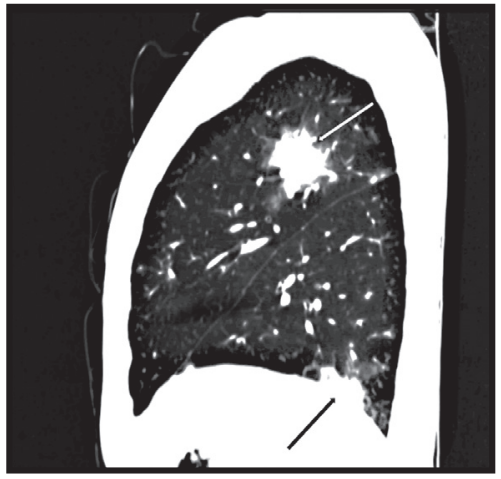

B

O paciente, de 15 anos, desenvolveu febre e erupção cutânea maculopapular difusa 21 dias antes da admissão hospitalar. Ele fez uso de antibióticos e sintomáticos sem melhora do quadro. Ao exame clínico, o adolescente aparentava bom desenvolvimento somático e encontrava-se emagrecido. A pele era pálida e a temperatura axilar elevada $(39,3$ 으. Não havia relato de diarréia. O fígado e o baço eram palpáveis e dolorosos. 0 hemograma revelou leucocitose $(38.000$ células $/ \mathrm{mL}$ ) e eosinofilia ( 30.400 células $/ \mathrm{mL}$ ); a contagem de plaquetas e o nível de hemoglobina eram normais. A alanina-aminotransferase estava ligeiramente aumentada no soro. A ultrassonografia abdominal confirmou aumento do fígado e do baço e identificou linfonodos periportais. No exame parasitológico das fezes, havia ovos viáveis de Schistosoma mansoni. O paciente relatou contato com águas naturais em área endêmica para esquistossomose 30 dias antes do adoecimento. Tomografia computadorizada (TC) helicoidal com reconstruções multiplanares e técnica MIP (maximum intension projection) demonstraram nódulos esparsos bilaterais e consolidação no lobo superior esquerdo (Figura A). Na reconstrução no plano sagital, observou-se no pulmão esquerdo duas consolidações pulmonares nos lobos superior e inferior (Figura B; setas).

\section{REFERENCES}

1. Lambertucci JR. Acute schistosomiasis mansoni: revisited and reconsidered. Mem Inst Oswaldo Cruz 2010; 105:422-435.

2. Lambertucci JR, Silva LC, Andrade LM, Queiroz LC, Carvalho VT, Voieta I, et al. Imaging techniques in the evaluation of morbidity in schistosomiasis mansoni. Acta Trop 2008; 108:209-217.

3. Voieta I, Andrade LM, Lambertucci JR. Magnetic resonance of the liver in acute schistosomiasis. Rev Soc Bras Med Trop 2011; 44:403. 